\title{
Cost-benefit analysis of a reliability model on water process system having two types of redundant subsystems
}

\author{
Rajeev Kumar*, Sunita Rani \\ Department of Mathematics, M. D. University, Rohtak, Haryana, INDIA \\ *Corresponding author E-mail: drrajeevmdu@gmail.com
}

\begin{abstract}
In this paper a reliability model on a water system working in Panipat Thermal Plant, Panipat is considered. It was observed while visiting the plant that the system is consist of several redundant and non-redundant sub-systems where redundant sub-systems are of two types i.e. 1-out-of-2 (type-I) and 2-out-of-3 (type-II). On the occurrence of a minor fault in any subsystem the system goes to partial failure whereas on occurrence of a major fault in the non-redundant subsystem it completely fails. On partial failure of the system, the repairman available first inspects whether the fault is in redundant subsystem or in non-redundant subsystem and accordingly carries out the repair of the subsystem involved. Various measures of system effectiveness are obtained by using Markov processes and regenerative point technique. Using these measures the system is analysed in terms of its reliability and cost and various conclusions are drawn on the basis of the graphical studies.
\end{abstract}

Keywords: Water process system, MTSF, Availability, Profit, Markov process, Regenerative point technique.

\section{Introduction}

In the field of reliability modeling including Garg and Kumar [1], Gupta and Kumar [3], Murari and Goyal [8], Goel et. al. [2], Kumar et al [4, 5], Kumar and Bhatia [6] have analyzed a large number of systems considering various concepts such as different failure modes, repairs, replacements, inspections, degraded etc.

A large number of water process systems are being used in modern industry that includes cooling water system, hot water system, waste water treatment plant, steam generating system and water circulation system etc. The reliability and cost of the water process systems plays a very important role to the industries involved hence need to be analysed. Recently, Kumar and Rani [7] discussed the reliability and availability analysis of a model on water process system having two types of redundant subsystems.

It was observed while visiting the Panipat Thermal Power Plant, Panipat that water process system used there has a significant role due to the dependency of whole process on circulation of water in different modes through various subsystems. Some subsystems are redundant like Raw Water Pump, Condensate Exhaust Pump and Boiler Feed Pump etc. and others are non-redundant like Gland Steam Cooler, Low Pressure Heater, Economizer and Boiler Drum etc. These subsystems have different type of faults, some of them are minor faults like Vibration in Motor of Raw Water Pump, Pump Tripping in Service Water Pump etc. and other are major faults like Casing leakage in main BFP, Cartridge damaged in BFP etc. The real data collected on water process system working there gives the following estimates:

$=199$

Probability that a fault occurs in a redundant subsystem of type-I

$=0.8895$

Probability that a fault occurs in a redundant subsystem of type-II

$=0.1105$

Rate of occurrence of major faults

$=0.0028$

Rate of occurrence of minor faults

$=0.0082$

Repair rate of fault occurs in redundant subsystem of type-I

$=0.0409$

Repair rate of fault occurs in redundant subsystem of type-II

$=0.428$

In the present paper, a water process system that consists of several redundant and non-redundant sub-systems where redundant sub-systems are of two types i.e. 1-out-of-2 (type-I) and 2-out-of-3 (type-II) is considered that exist in Panipat Thermal Power Plant, Panipat. It is assumed that the system goes to partial failure on the occurrence of a minor fault in any of the subsystem whereas it completely fails on occurrence of a major fault 
in the non-redundant/redundant subsystem. On partial failure of the system, the repairman available first inspects whether the fault is in redundant or in non-redundant and if fault is found in redundant system than he will inspect whether the fault is in type-I or type-II redundant subsystem and accordingly carries out the repair of the subsystem involved. Various measures of system effectiveness are obtained by using Markov processes and regenerative point technique. The conclusions regarding the reliability and cost for the system are drawn on the basis of graphical studies.

\section{Other assumptions}

(i) All faults are self- announcing.

(ii) There is a single repair facility.

(iii) The priority for repair is given to the non-redundant subsystem on occurrence of major fault.

(iv) The times to repair the unit on occurrence of major or minor faults by the repairman in redundant and nonredundant subsystem are different.

(v) The system is as good as new after each repair.

(vi) The switching is perfect and instantaneous.

(vii) The failure time distributions are exponential while other time distributions are general.

\section{States of the system}

$\begin{array}{lll}\mathrm{O} & : & \text { Operative system. } \\ \mathrm{Oi} & : & \text { Operative system under inspection. } \\ \mathrm{O}_{\mathrm{NRDr}} & : & \text { Operative non-redundant subsystem under repair. } \\ \mathrm{O}_{\mathrm{RDi}} & : & \text { Operative redundant subsystem under repair. } \\ \mathrm{O}_{\mathrm{RD}-\mathrm{I}} / \mathrm{O}_{\mathrm{RD}-\mathrm{Ir}} & : & \text { Operative / under repair redundant subsystem of (type-I). } \\ \mathrm{O}_{\mathrm{RD}-\mathrm{II}} / \mathrm{O}_{\mathrm{RD}-\mathrm{IIr}} & : & \text { Operative / under repair redundant subsystem of (type-II). } \\ \mathrm{F}_{\mathrm{r}} & : & \text { Failed system under repair. }\end{array}$

\section{Notations}

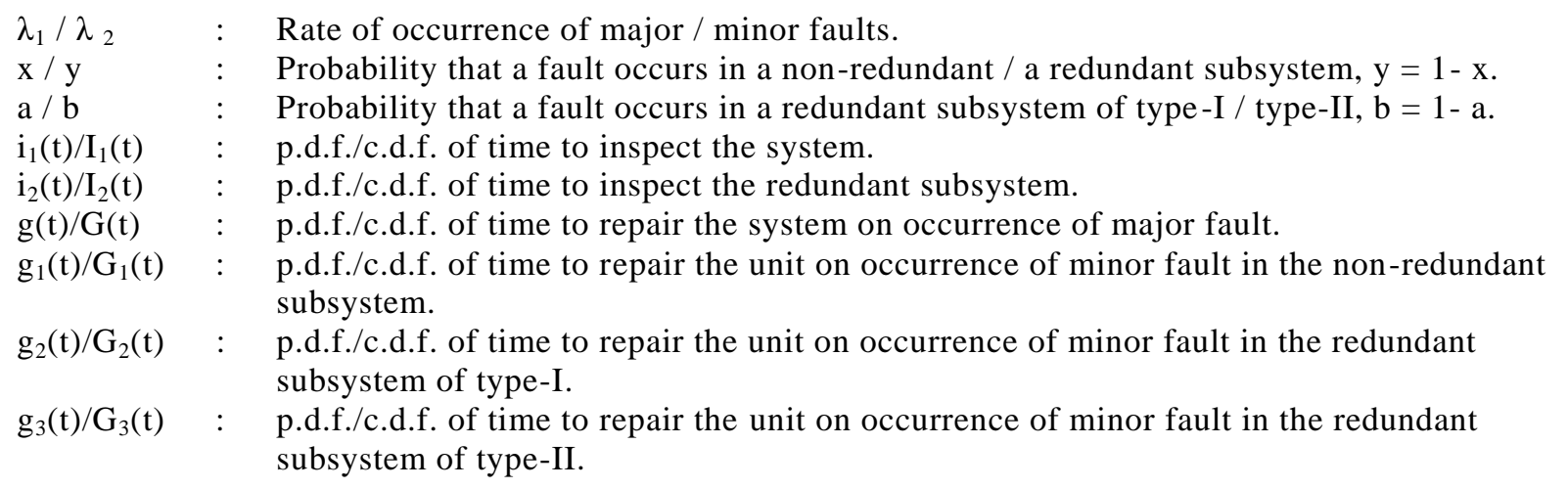

\section{Transition probabilities and mean sojourn times}

A transition diagram showing the various states of transition is shown as Fig.1. The epochs of entry in to state $0,1,2,3$, $4,5,6$ are regenerative point, i.e. all the states are regenerative state 


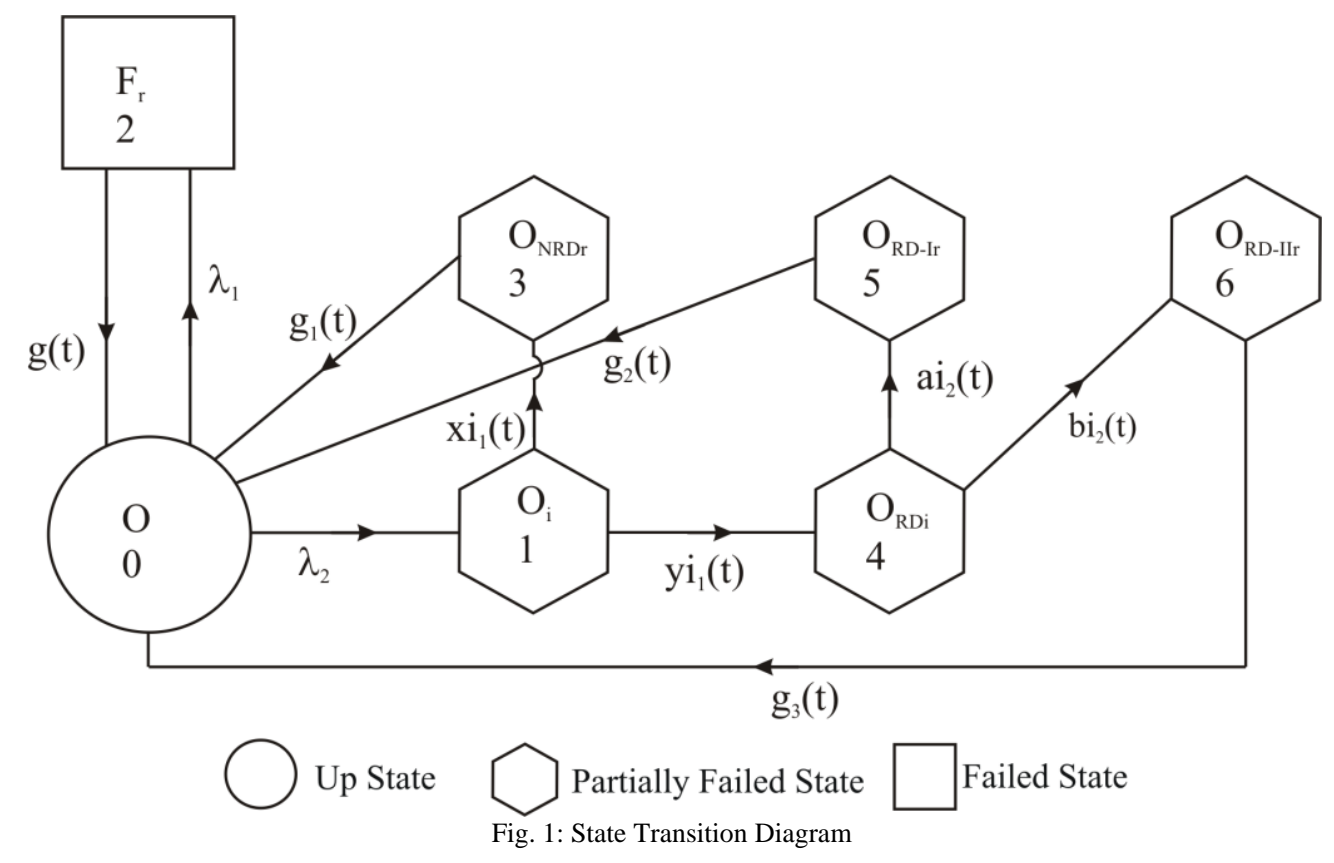

The transition probabilities are

$$
\begin{array}{lll}
\mathrm{dQ}_{01}(\mathrm{t})=\lambda_{2} \mathrm{e}^{-\left(\lambda_{1}+\lambda_{2}\right) \mathrm{t}} \mathrm{dt} & \mathrm{dQ}_{02}(\mathrm{t})=\lambda_{1} \mathrm{e}^{-\left(\lambda_{1}+\lambda_{2}\right) \mathrm{t}} \mathrm{dt} & \mathrm{dQ}_{13}(\mathrm{t})=\mathrm{xi}_{1}(\mathrm{t}) \mathrm{dt} \\
\mathrm{dQ}_{14}(\mathrm{t})=\mathrm{yi}_{1}(\mathrm{t}) \mathrm{dt} & \mathrm{dQ}_{20}(\mathrm{t})=\mathrm{g}(\mathrm{t}) \mathrm{dt} & \mathrm{dQ} \mathrm{Q}_{30}(\mathrm{t})=\mathrm{g}_{1}(\mathrm{t}) \mathrm{dt} \\
\mathrm{dQ}_{45}(\mathrm{t})=\mathrm{ai}_{2}(\mathrm{t}) \mathrm{dt} & \mathrm{dQ}_{46}(\mathrm{t})=\mathrm{bi}_{2}(\mathrm{t}) \mathrm{dt} & \mathrm{dQ}_{50}(\mathrm{t})=\mathrm{g}_{2}(\mathrm{t}) \mathrm{dt} \\
\mathrm{dQ}_{60}(\mathrm{t})=\mathrm{g}_{3}(\mathrm{t}) \mathrm{dt} & &
\end{array}
$$

The non-zero elements $\mathrm{p}_{\mathrm{ij}}=\lim _{\mathrm{t} \rightarrow \infty} \mathrm{Q}_{\mathrm{ij}}(\mathrm{t})$ are

$$
\begin{array}{lllll}
\mathrm{p}_{01}=\frac{\lambda_{2}}{\lambda_{1}+\lambda_{2}} & \mathrm{p}_{02}=\frac{\lambda_{1}}{\lambda_{1}+\lambda_{2}} & \mathrm{p}_{13}=\mathrm{xi}_{1}^{*}(0) & \mathrm{p}_{14}=\mathrm{yi}_{1}^{*}(0) & \mathrm{p}_{20}=\mathrm{g}^{*}(0) \\
\mathrm{p}_{30}=\mathrm{g}_{1}^{*}(0) & \mathrm{p}_{45}=\mathrm{ai}_{2}^{*}(0) & \mathrm{p}_{46}=\mathrm{bi}_{2}^{*}(0) & \mathrm{p}_{50}=\mathrm{g}_{2}^{*}(0) & \mathrm{p}_{60}=\mathrm{g}_{3}^{*}(0)
\end{array}
$$

By these transition probabilities, it can be verified that
$\mathrm{p}_{01}+\mathrm{p}_{02}=1$
$\mathrm{p}_{13}+\mathrm{p}_{14}=1$
$\mathrm{p}_{45}+\mathrm{p}_{46}=1$
$\mathrm{p}_{20}=\mathrm{p}_{30}=\mathrm{p}_{50}=\mathrm{p}_{60}=1$

The unconditional mean time taken by the system to transit for any regenerative state $\mathrm{j}$, when it is counted from epoch of entrance into that state $i$, is mathematically stated as

$$
\begin{aligned}
& \mathrm{m}_{\mathrm{ij}}=\int_{0}^{\infty} \mathrm{tdQ}_{\mathrm{ij}}(\mathrm{t})=-\mathrm{q}_{\mathrm{ij}}^{* \prime}(0) \text {, thus } \\
& \mathrm{m}_{01}+\mathrm{m}_{02}=\mu_{0} \text {, } \\
& \mathrm{m}_{13}+\mathrm{m}_{14}=\mu_{1}, \\
& \mathrm{~m}_{20}=\mu_{2} \text {, } \\
& \mathrm{m}_{30}=\mu_{3}, \\
& \mathrm{~m}_{45}+\mathrm{m}_{46}=\mu_{4} \text {, } \\
& \mathrm{m}_{50}=\mu_{5} \text {, } \\
& \mathrm{m}_{60}=\mu_{6}
\end{aligned}
$$

The mean sojourn time $\left(\mu_{\mathrm{i}}\right)$ in the regenerative state ' $\mathrm{i}$ ' is defined as the time of stay in that state before transition to any other state. If $\mathrm{T}$ denotes the sojourn time in regenerative state $\mathrm{i}$, then

$$
\begin{array}{lll}
\mu_{0}=\frac{1}{\lambda_{1}+\lambda_{2}}, & \mu_{1}=-\mathrm{i}_{1}^{* \prime}(0), & \mu_{2}=-\mathrm{g}^{* \prime}(0), \\
\mu_{4}=-\mathrm{i}_{2}^{* \prime}(0), & \mu_{5}=-\mathrm{g}_{2}^{* \prime}(0), & \mu_{6}=-\mathrm{g}_{3}^{* \prime}(0)
\end{array}
$$

\section{Mean time to system failure}

To determine the MTSF of the system, we regard the failed states of the system as absorbing states. By probabilistic arguments, we obtain the following recursive relations for $\phi_{i}(t)$, c.d.f of the first passage time from regenerative state $i$ to failed state: 


$$
\begin{aligned}
& \phi_{0}(\mathrm{t})=\mathrm{Q}_{01}(\mathrm{t}) \oplus \phi_{1}(\mathrm{t})+\mathrm{Q}_{02}(\mathrm{t}) \\
& \phi_{1}(\mathrm{t})=\mathrm{Q}_{13}(\mathrm{t}) \oplus{ }^{\oplus}(\mathrm{t})+\mathrm{Q}_{14}(\mathrm{t}){ }^{\oplus} \phi_{4}(\mathrm{t}) \\
& \phi_{3}(\mathrm{t})=\mathrm{Q}_{30}(\mathrm{t}) \oplus \phi_{0}(\mathrm{t}) \\
& \phi_{4}(\mathrm{t})=\mathrm{Q}_{45}(\mathrm{t}) \oplus \phi_{5}(\mathrm{t})+\mathrm{Q}_{46}(\mathrm{t}){ }^{\oplus} \phi_{6}(\mathrm{t}) \\
& \phi_{5}(\mathrm{t})=\mathrm{Q}_{50}(\mathrm{t}) \oplus \phi_{0}(\mathrm{t}) \\
& \phi_{6}(\mathrm{t})=\mathrm{Q}_{60}(\mathrm{t}) \stackrel{\oplus}{\oplus} \phi_{0}(\mathrm{t})
\end{aligned}
$$

Taking L.S.T. of these equations and solving for $\phi_{0}{ }^{* *}(\mathrm{~s})$, we obtain

$$
\phi_{0}^{* *}(\mathrm{~s})=\frac{\mathrm{N}(\mathrm{s})}{\mathrm{D}(\mathrm{s})}
$$

The mean time to system failure (MTSF) when the system starts from the state 0 , is

$$
\begin{aligned}
\mathrm{T}_{0} & =\lim _{\mathrm{s} \rightarrow 0} \frac{1-\phi_{0} * *(\mathrm{~s})}{\mathrm{s}}=\frac{\mathrm{N}}{\mathrm{D}} \\
\text { where } \quad \mathrm{N} & =\mu_{0}+\mathrm{p}_{01}\left[\mu_{1}+\mathrm{p}_{13} \mu_{3}+\mathrm{p}_{14}\left(\mu_{4}+\mathrm{p}_{45} \mu_{5}+\mathrm{p}_{46} \mu_{6}\right)\right] \\
\mathrm{D} & =1-\mathrm{p}_{01}\left[\mathrm{p}_{13} \mathrm{p}_{30}+\mathrm{p}_{14}\left(\mathrm{p}_{45} \mathrm{p}_{50}+\mathrm{p}_{46} \mathrm{p}_{60}\right)\right]
\end{aligned}
$$

\section{Expected up-time of the system with full capacity}

Using the arguments of the theory of regenerative processes, the availability $\mathrm{AF}_{\mathrm{i}}(\mathrm{t})$, the probability that the system is up at instant ' $t$ ' with full capacity given that it entered regenerative state ' $i$ ' at $t=0$, satisfies the following recursive relations

$$
\begin{aligned}
& \mathrm{AF}_{0}(\mathrm{t})=\mathrm{M}_{0}(\mathrm{t})+\mathrm{q}_{01}(\mathrm{t}) \odot \mathrm{AF}_{1}(\mathrm{t})+\mathrm{q}_{02}(\mathrm{t}) \odot \mathrm{AF}_{2}(\mathrm{t}) \\
& \mathrm{AF}_{1}(\mathrm{t})=\mathrm{q}_{13}(\mathrm{t}) \odot \mathrm{AF}_{3}(\mathrm{t})+\mathrm{q}_{14}(\mathrm{t}) \odot \mathrm{AF}_{4}(\mathrm{t}) \\
& \mathrm{AF}_{2}(\mathrm{t})=\mathrm{q}_{20}(\mathrm{t}) \odot \mathrm{AF}_{0}(\mathrm{t}) \\
& \mathrm{AF}_{3}(\mathrm{t})=\mathrm{q}_{30}(\mathrm{t}) \odot \mathrm{AF}_{0}(\mathrm{t}) \\
& \mathrm{AF}_{4}(\mathrm{t})=\mathrm{q}_{45}(\mathrm{t}) \odot \mathrm{AF}_{5}(\mathrm{t})+\mathrm{q}_{46}(\mathrm{t}) \odot \mathrm{AF}_{6}(\mathrm{t}) \\
& \mathrm{AF}_{5}(\mathrm{t})=\mathrm{q}_{50}(\mathrm{t}) \odot \mathrm{AF}_{0}(\mathrm{t}) \\
& \mathrm{AF}_{6}(\mathrm{t})=\mathrm{q}_{60}(\mathrm{t}) \odot \mathrm{AF}_{0}(\mathrm{t})
\end{aligned}
$$

where $\mathrm{M}_{0}(\mathrm{t})=\mathrm{e}^{-\left(\lambda_{1}+\lambda_{2}\right) \mathrm{t}}$

Taking Laplace transform of the above equations and solving for $\mathrm{AF}_{0} *(\mathrm{~s})$, we have

$$
\mathrm{AF}_{0}^{*}(\mathrm{~s})=\frac{\mathrm{N}_{1}(\mathrm{~s})}{\mathrm{D}_{1}(\mathrm{~s})}
$$

In steady state the expected up-time of the system with full capacity is given by

$$
\mathrm{AF}_{0}=\lim _{\mathrm{s} \rightarrow 0}\left(\mathrm{sAF}_{0}^{*}(\mathrm{~s})\right)=\frac{\mathrm{N}_{1}}{\mathrm{D}_{1}}
$$

where $\mathrm{N}_{1}=\mu_{0}$

$$
D_{1}=\mu_{0}+p_{02} \mu_{2}+p_{01}\left[\mu_{1}+p_{13} \mu_{3}+p_{14}\left(\mu_{4}+p_{45} \mu_{5}+p_{46} \mu_{6}\right)\right]
$$

\section{Expected up-time of the system with reduced capacity}

In the similar way, the availability $\mathrm{AR}_{\mathrm{i}}(\mathrm{t})$, the probability that the system is up at instant ' $\mathrm{t}$ ' with reduced capacity given that it entered regenerative state ' $\mathrm{i}$ ' at $\mathrm{t}=0$, satisfies the following recursive relations

$$
\begin{aligned}
& \operatorname{AR}_{0}(\mathrm{t})=\mathrm{q}_{01}(\mathrm{t}) \odot \mathrm{AR}_{1}(\mathrm{t})+\mathrm{q}_{02}(\mathrm{t}) \odot \mathrm{AR}_{2}(\mathrm{t}) \\
& \mathrm{AR}_{1}(\mathrm{t})=\mathrm{M}_{1}(\mathrm{t})+\mathrm{q}_{13}(\mathrm{t}) \odot \mathrm{AR}_{3}(\mathrm{t})+\mathrm{q}_{14}(\mathrm{t}) \odot \mathrm{AR}_{4}(\mathrm{t})
\end{aligned}
$$




$$
\begin{array}{ll}
\mathrm{AR}_{2}(\mathrm{t})=\mathrm{q}_{20}(\mathrm{t}) \oplus \mathrm{AR}_{0}(\mathrm{t}) \\
\mathrm{AR}_{3}(\mathrm{t})=\mathrm{M}_{3}(\mathrm{t})+\mathrm{q}_{30}(\mathrm{t}) \oplus \mathrm{AR}_{0}(\mathrm{t}) \\
\mathrm{AR}_{4}(\mathrm{t})=\mathrm{M}_{4}(\mathrm{t})+\mathrm{q}_{45}(\mathrm{t}) \oplus \mathrm{AR}_{5}(\mathrm{t})+\mathrm{q}_{46}(\mathrm{t}) \oplus \mathrm{AR}_{6}(\mathrm{t}) \\
\mathrm{AR}_{5}(\mathrm{t})=\mathrm{M}_{5}(\mathrm{t})+\mathrm{q}_{50}(\mathrm{t}) \oplus \mathrm{AR}_{0}(\mathrm{t}) \\
\mathrm{AR}_{6}(\mathrm{t})=\mathrm{M}_{6}(\mathrm{t})+\mathrm{q}_{60}(\mathrm{t}) \oplus \mathrm{AR}_{0}(\mathrm{t}) \\
\mathrm{M} \quad \mathrm{M}_{3}(\mathrm{t})=\overline{\mathrm{G}_{1}}(\mathrm{t}) ; \quad \mathrm{M}_{4}(\mathrm{t})=\overline{\mathrm{I}_{2}}(\mathrm{t}) ; \quad \mathrm{M}_{5}(\mathrm{t})=\overline{\mathrm{G}_{2}}(\mathrm{t}) ; \\
\left.\mathrm{M}_{1}(\mathrm{t})=\overline{\mathrm{I}_{1}}(\mathrm{t}) ; \quad \mathrm{G}\right)=\overline{\mathrm{G}_{3}}(\mathrm{t}) \quad
\end{array}
$$

Taking Laplace transform of the above equations and solving for $\mathrm{AR}_{0} *(\mathrm{~s})$, we have

$$
\operatorname{AR}_{0}^{*}(\mathrm{~s})=\frac{\mathrm{N}_{2}(\mathrm{~s})}{\mathrm{D}_{1}(\mathrm{~s})}
$$

In steady state the expected up-time of the system with reduced capacity is given by

$$
\begin{array}{ll} 
& \mathrm{AR}_{0}=\lim _{\mathrm{s} \rightarrow 0}\left(\operatorname{sAR}_{0}^{*}(\mathrm{~s})\right)=\frac{\mathrm{N}_{2}}{\mathrm{D}_{1}} \\
\text { where } & \mathrm{N}_{2}=\mathrm{p}_{01}\left[\mu_{1}+\mathrm{p}_{13} \mu_{3}+\mathrm{p}_{14}\left(\mu_{4}+\mathrm{p}_{45} \mu_{5}+\mathrm{p}_{46} \mu_{6}\right)\right] \\
& \mathrm{D}_{1}=\mu_{0}+\mathrm{p}_{02} \mu_{2}+\mathrm{p}_{01}\left[\mu_{1}+\mathrm{p}_{13} \mu_{3}+\mathrm{p}_{14}\left(\mu_{4}+\mathrm{p}_{45} \mu_{5}+\mathrm{p}_{46} \mu_{6}\right)\right]
\end{array}
$$

\section{Busy period of repair man (inspection time only)}

Using the probabilistic argument for regenerative process we obtained the following recursive relations for $\mathrm{B}_{\mathrm{i}}(\mathrm{t})$

$$
\begin{aligned}
& \mathrm{B}_{0}(\mathrm{t})=\mathrm{q}_{01}(\mathrm{t}) \odot \mathrm{B}_{1}(\mathrm{t})+\mathrm{q}_{02}(\mathrm{t}) \odot \mathrm{B}_{2}(\mathrm{t}) \\
& \mathrm{B}_{1}(\mathrm{t})=\mathrm{W}_{1}(\mathrm{t})+\mathrm{q}_{13}(\mathrm{t}) \odot \mathrm{B}_{3}(\mathrm{t})+\mathrm{q}_{14}(\mathrm{t}) \odot \mathrm{B}_{4}(\mathrm{t}) \\
& \mathrm{B}_{2}(\mathrm{t})=\mathrm{q}_{20}(\mathrm{t}) \odot \mathrm{B}_{0}(\mathrm{t}) \\
& \mathrm{B}_{3}(\mathrm{t})=\mathrm{q}_{30}(\mathrm{t}) \odot \mathrm{B}_{0}(\mathrm{t}) \\
& \mathrm{B}_{4}(\mathrm{t})=\mathrm{W}_{4}(\mathrm{t})+\mathrm{q}_{45}(\mathrm{t}) \odot \mathrm{B}_{5}(\mathrm{t})+\mathrm{q}_{46}(\mathrm{t}) \odot \mathrm{B}_{6}(\mathrm{t}) \\
& \mathrm{B}_{5}(\mathrm{t})=\mathrm{q}_{50}(\mathrm{t}) \odot \mathrm{B}_{0}(\mathrm{t}) \\
& \mathrm{B}_{6}(\mathrm{t})=\mathrm{q}_{60}(\mathrm{t}) \odot \mathrm{B}_{0}(\mathrm{t})
\end{aligned}
$$

where $\mathrm{W}_{1}(\mathrm{t})=\overline{\mathrm{I}}_{1}(\mathrm{t}) ; \quad \mathrm{W}_{4}(\mathrm{t})=\overline{\mathrm{I}_{2}}(\mathrm{t})$

Taking Laplace transform of the above equations and solving for $\mathrm{B}_{\mathrm{i}}^{*}(\mathrm{~s})$, we have

$$
\mathrm{B}_{\mathrm{i}}^{*}(\mathrm{~s})=\frac{\mathrm{N}_{3}(\mathrm{~s})}{\mathrm{D}_{1}(\mathrm{~s})}
$$

In steady state busy period of the repairman for inspection of the system is given by

$$
\begin{array}{ll} 
& \mathrm{B}_{\mathrm{i}}=\lim _{\mathrm{s} \rightarrow 0}\left(\mathrm{sB}_{\mathrm{i}}^{*}(\mathrm{~s})\right)=\frac{\mathrm{N}_{3}}{\mathrm{D}_{1}} \\
\text { where } & \mathrm{N}_{3}=\mathrm{p}_{01}\left(\mu_{1}+\mathrm{p}_{14} \mu_{4}\right) \\
& \mathrm{D}_{1}=\text { already defined }
\end{array}
$$

\section{Busy period of repair man (repair time only)}

Using the probabilistic argument for regenerative process we obtained the following recursive relations for $\mathrm{B}_{\mathrm{i}}(\mathrm{t})$

$$
\begin{aligned}
& \mathrm{B}_{0}(\mathrm{t})=\mathrm{q}_{01}(\mathrm{t}) \odot \mathrm{B}_{1}(\mathrm{t})+\mathrm{q}_{02}(\mathrm{t}) \oplus \mathrm{B}_{2}(\mathrm{t}) \\
& \mathrm{B}_{1}(\mathrm{t})=\mathrm{q}_{13}(\mathrm{t}) \odot \mathrm{B}_{3}(\mathrm{t})+\mathrm{q}_{14}(\mathrm{t}) \odot \mathrm{B}_{4}(\mathrm{t}) \\
& \mathrm{B}_{2}(\mathrm{t})=\mathrm{W}_{2}(\mathrm{t})+\mathrm{q}_{20}(\mathrm{t}) \odot \mathrm{B}_{0}(\mathrm{t}) \\
& \mathrm{B}_{3}(\mathrm{t})=\mathrm{W}_{3}(\mathrm{t})+\mathrm{q}_{30}(\mathrm{t}) \odot \mathrm{B}_{0}(\mathrm{t})
\end{aligned}
$$




$$
\begin{aligned}
& \mathrm{B}_{4}(\mathrm{t})=\mathrm{q}_{45}(\mathrm{t}) \odot \mathrm{B}_{5}(\mathrm{t})+\mathrm{q}_{46}(\mathrm{t}) \odot \mathrm{B}_{6}(\mathrm{t}) \\
& \mathrm{B}_{5}(\mathrm{t})=\mathrm{W}_{5}(\mathrm{t})+\mathrm{q}_{50}(\mathrm{t}) \oplus \mathrm{B}_{0}(\mathrm{t}) \\
& \mathrm{B}_{6}(\mathrm{t})=\mathrm{W}_{6}(\mathrm{t})+\mathrm{q}_{60}(\mathrm{t}) \odot \mathrm{B}_{0}(\mathrm{t})
\end{aligned}
$$
where $\mathrm{W}_{2}(\mathrm{t})=\overline{\mathrm{G}}(\mathrm{t})$;
$\mathrm{W}_{3}(\mathrm{t})=\overline{\mathrm{G}_{1}}(\mathrm{t})$
$\mathrm{W}_{5}(\mathrm{t})=\overline{\mathrm{G}_{2}}(\mathrm{t})$;
$\mathrm{W}_{6}(\mathrm{t})=\overline{\mathrm{G}_{3}}(\mathrm{t})$

Taking Laplace transform of the above equations and solving for $\mathrm{B}_{\mathrm{r}}{ }^{*}(\mathrm{~s})$, we have

$$
\mathrm{B}_{\mathrm{r}}^{*}(\mathrm{~s})=\frac{\mathrm{N}_{4}(\mathrm{~s})}{\mathrm{D}_{1}(\mathrm{~s})}
$$

In steady state busy period of the repairman for repair of the system is given by

$$
B_{r}=\lim _{s \rightarrow 0}\left(s B_{r}^{*}(s)\right)=\frac{N_{4}}{D_{1}}
$$

where $\quad \mathrm{N}_{4}=\mathrm{p}_{02} \mu_{2}+\mathrm{p}_{01}\left[\mathrm{p}_{13} \mu_{3}+\mathrm{p}_{14}\left(\mathrm{p}_{45} \mu_{5}+\mathrm{p}_{46} \mu_{6}\right)\right]$

$\mathrm{D}_{1}=$ already defined

\section{Profit analysis}

The expected profit incurred of the system is:

$$
\mathrm{P}=\mathrm{C}_{0} \mathrm{AF}_{0}+\mathrm{C}_{1} \mathrm{AR}_{0}-\mathrm{C}_{2} \mathrm{~B}_{\mathrm{i}}-\mathrm{C}_{3} \mathrm{~B}_{\mathrm{r}}-\mathrm{C}_{4}
$$

where $\mathrm{C}_{0}=$ revenue per unit uptime of the system working with full capacity.

$\mathrm{C}_{1}=$ revenue per unit uptime of the system working with reduced capacity.

$\mathrm{C}_{2}=$ cost per unit time of inspection of the failed unit

$\mathrm{C}_{3}=$ cost per unit time of repair of the failed unit

$\mathrm{C}_{4}=$ cost of installation

\section{Graphical interpretation}

For graphical analysis following particular cases are considered-

$$
\begin{array}{lll}
\mathrm{i}_{1}(\mathrm{t})=\alpha_{1} \mathrm{e}^{-\alpha_{1}(\mathrm{t})} ; & \mathrm{i}_{2}(\mathrm{t})=\alpha_{2} \mathrm{e}^{-\alpha_{2}(\mathrm{t})} ; & \mathrm{g}(\mathrm{t})=\beta \mathrm{e}^{-\beta(\mathrm{t})} ; \\
\mathrm{g}_{1}(\mathrm{t})=\beta_{1} \mathrm{e}^{-\beta_{1}(\mathrm{t})} ; & \mathrm{g}_{2}(\mathrm{t})=\beta_{2} \mathrm{e}^{-\beta_{2}(\mathrm{t})} ; & \mathrm{g}_{3}(\mathrm{t})=\beta_{3} \mathrm{e}^{-\beta_{3}(\mathrm{t})}
\end{array}
$$

Various graphs are plotted for MTSF and profit of the system by taking different values of failure rates $\left(\lambda_{1}\right.$ and $\left.\lambda_{2}\right)$, repair rates $\left(\beta, \beta_{1}, \beta_{2}\right.$ and $\left.\beta_{3}\right)$ and inspection rates $\left(\alpha_{1}\right.$ and $\left.\alpha_{2}\right)$.

Fig. 2 gives the graph between MTSF $\left(T_{0}\right)$ and the failure rate $\left(\lambda_{2}\right)$ due to minor faults for different values of failure rate $\left(\lambda_{1}\right)$ due to major faults. The graph reveals that the MTSF deceases with increase in the values of the failure rates due to minor faults.

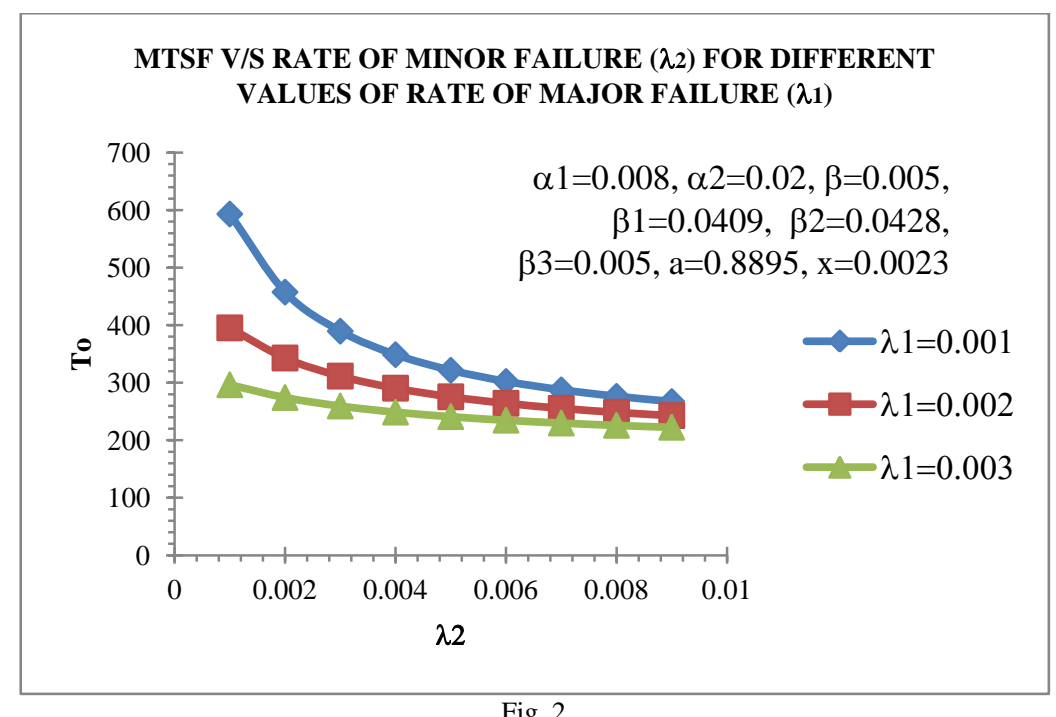


Fig. 3 shows the graph between MTSF $\left(\mathrm{T}_{0}\right)$ and the probability of fault occurrence in redundant subsystem of type-I (a) for different values of failure rate $\left(\lambda_{1}\right)$ due to major faults. The graph reveals that the MTSF deceases with increase in the values of the probability (a).

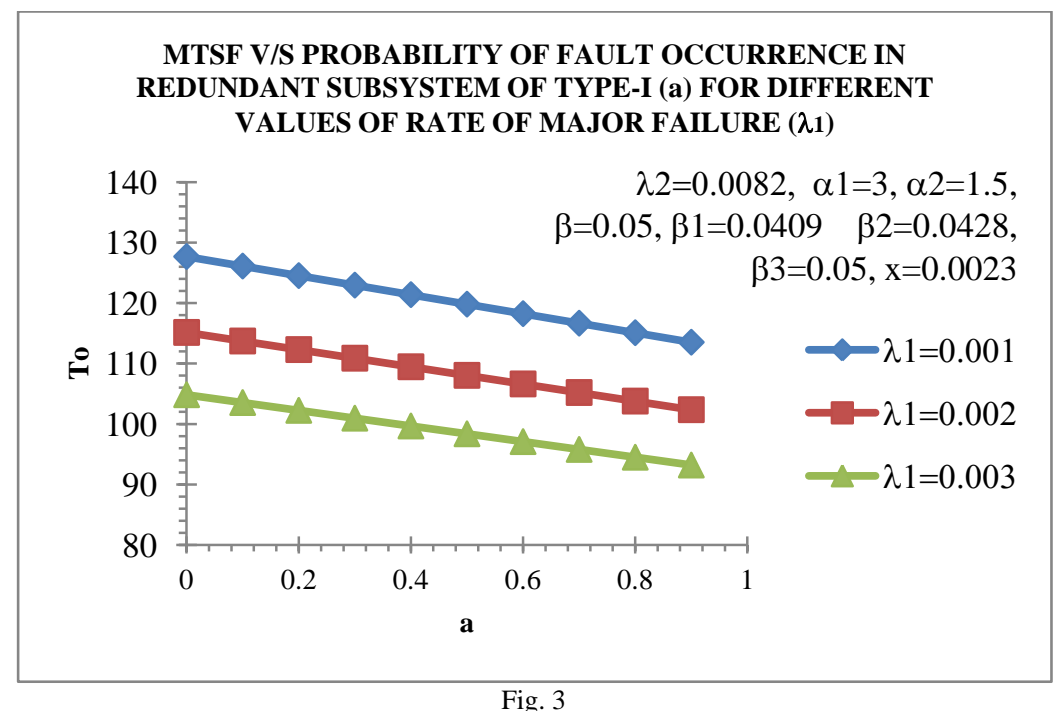

Fig. 4 depicts the behaviour of the profit with respect to rate of occurrence of minor faults $\left(\lambda_{2}\right)$ of the system for the different values of rate of occurrence major faults $\left(\lambda_{1}\right)$. It is evident from the graph that the profit decreases with the increase in the rate due to occurrence of minor faults and major faults respectively when other parameters remain fixed. For $\lambda_{1}=0.001$, the profit is $>$ or $=$ or $<0$ according as $\lambda_{2}$ is $<$ or $=$ or $>0.00783$. Hence the system is profitable to the company whenever $\lambda_{2}<0.00783$. For $\lambda_{1}=0.0012$ and for $\lambda_{1}=0.0014$ respectively the profit is $>$ or $=$ or $<0$ according as $\lambda_{2}$ is $<$ or $=$ or $>0.00582$ and 0.00367 respectively. Thus, in these cases, the system is profitable to the company whenever $\lambda_{2}<0.00582$ and 0.00367 respectively.

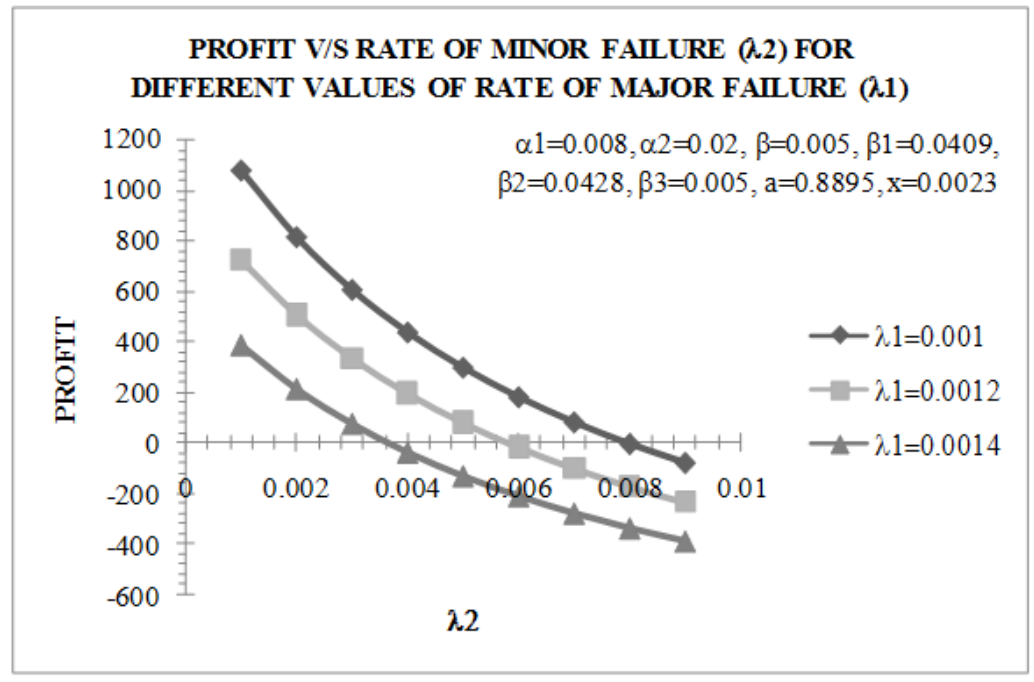

Fig. 4

Fig. 5 depicts the graphs between profit of the system and revenue per unit up-time of the system with full capacity $\left(\mathrm{C}_{0}\right)$ for different values of rate of occurrence of major faults $\left(\lambda_{1}\right)$. The graph reveals that the profit of the system increases with increase in the values of revenue per unit up-time of the system with full capacity and rate of occurrence of major faults. From the Fig.5 it may also be observed that for $\lambda_{1}=0.001$, the profit is $<$ or $=$ or $>0$ according as $\mathrm{C}_{0}$ is $<$ or $=$ or $>14368.79$. Hence the system is profitable to the plant whenever $\mathrm{C}_{0}>$ Rs.14368.79. Similarly, for $\lambda_{1}=0.0012$ and $\lambda_{1}=0.0014$ respectively the profit is $<$ or $=$ or $>0$ according as $\mathrm{C}_{0}$ is $\langle$ or $=$ or $>14840.08$ and 15348.69 respectively. Thus, in these cases, the system is profitable to the plant whenever $\mathrm{C}_{0}>$ Rs. 14840.08 and Rs. 15348.69 respectively. 


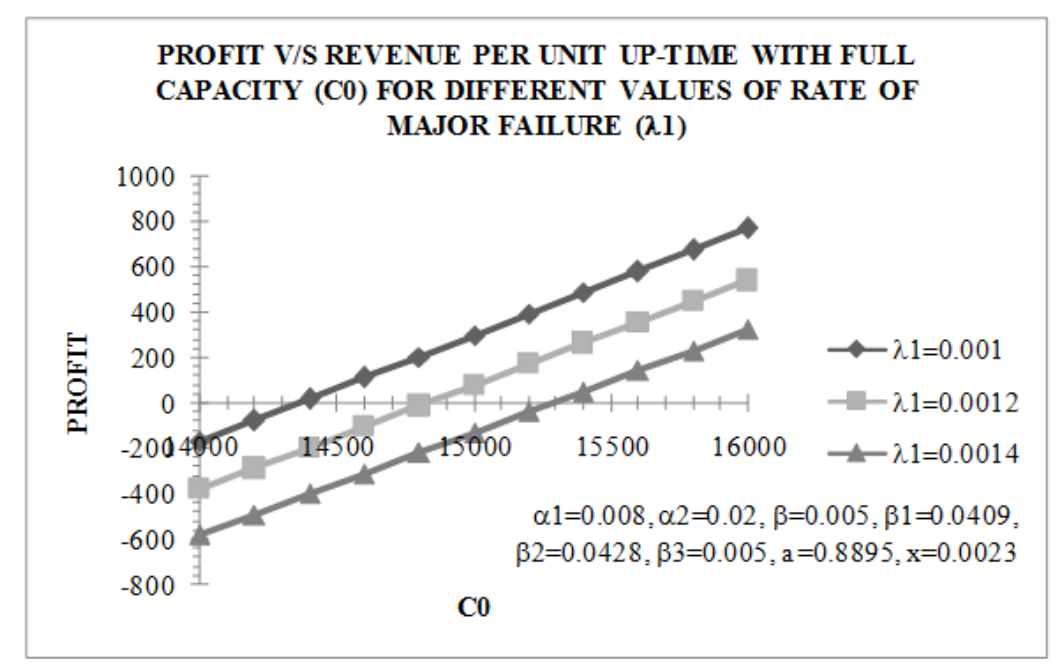

Fig. 5

Fig. 6 shows the graphs between profit of the system and revenue per unit up-time of the system with full capacity $\left(\mathrm{C}_{0}\right)$ for different values of inspection rate $\left(\alpha_{1}\right)$. The graph reveals that the profit of the system increases with increase in the values of revenue per unit up-time of the system with full capacity and the inspection rate. From the Fig. 6 it may also be observed that for $\alpha_{1}=0.015$, the profit is $<$ or $=$ or $>0$ according as $C_{0}$ is $<$ or $=$ or $>18732.61$. Hence the system is profitable to the plant whenever $C_{0}>$ Rs. 18732.61. Similarly, for $\alpha_{1}=0.030$ and $\alpha_{1}=0.045$ respectively the profit is $<$ or $=$ or $>0$ according as $\mathrm{C}_{0}$ is $<$ or $=$ or $>18542.95$ and 18478.79 respectively. Thus, in these cases, the system is profitable to the plant whenever $\mathrm{C}_{0}>$ Rs. 18542.95 and Rs. 18478.79 respectively.

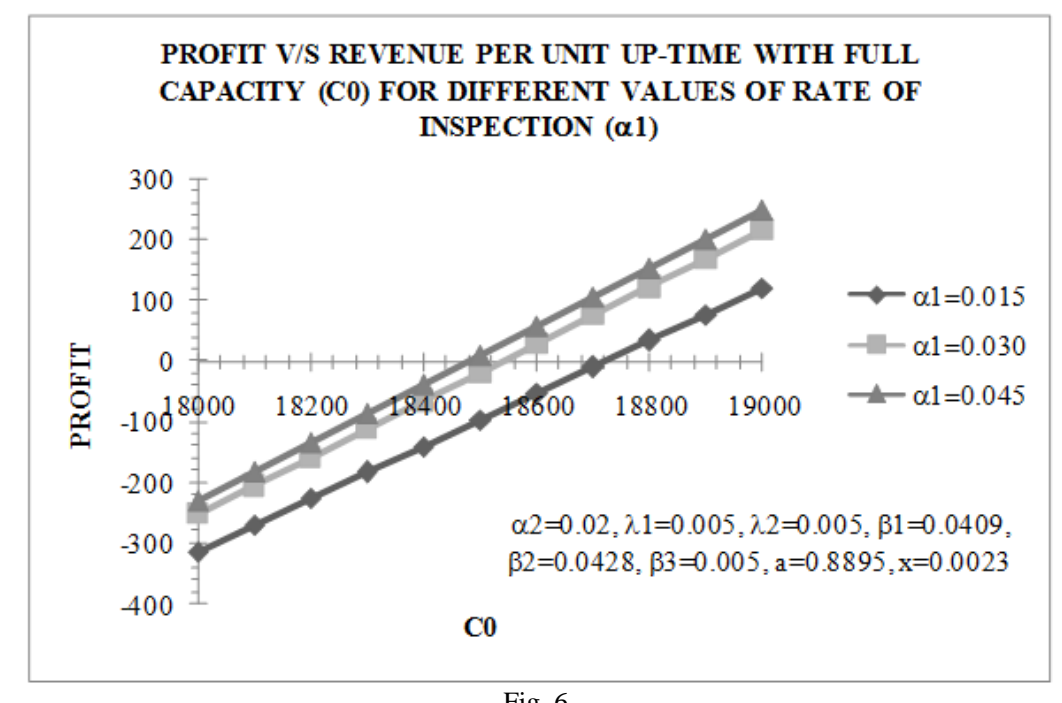

Fig. 6

Fig. 7 shows the graphs between profit of the system and revenue per unit up-time of the system with reduced capacity $\left(C_{1}\right)$ for different values of rate of occurrence of major faults $\left(\lambda_{1}\right)$. The graph reveals that the profit of the system increases with increase in the values of revenue per unit up-time of the system with reduced capacity and rate of occurrence of major faults. From the Fig.7 it may also be observed that for $\lambda_{1}=0.001$, the profit is $\langle$ or $=$ or $>0$ according as $C_{1}$ is $<$ or $=$ or $>9326.943$. Hence the system is profitable to the plant whenever $C_{1}>$ Rs. 9326.943 . Similarly, for $\lambda_{1}=0.0012$ and $\lambda_{1}=0.0014$ respectively the profit is $<$ or $=$ or $>0$ according as $C_{1}$ is $<$ or $=$ or $>9840.082$ and 10324.27 respectively. Thus, in these cases, the system is profitable to the plant whenever $C_{1}>$ Rs. 9840.082 and Rs. 10324.27 respectively. 


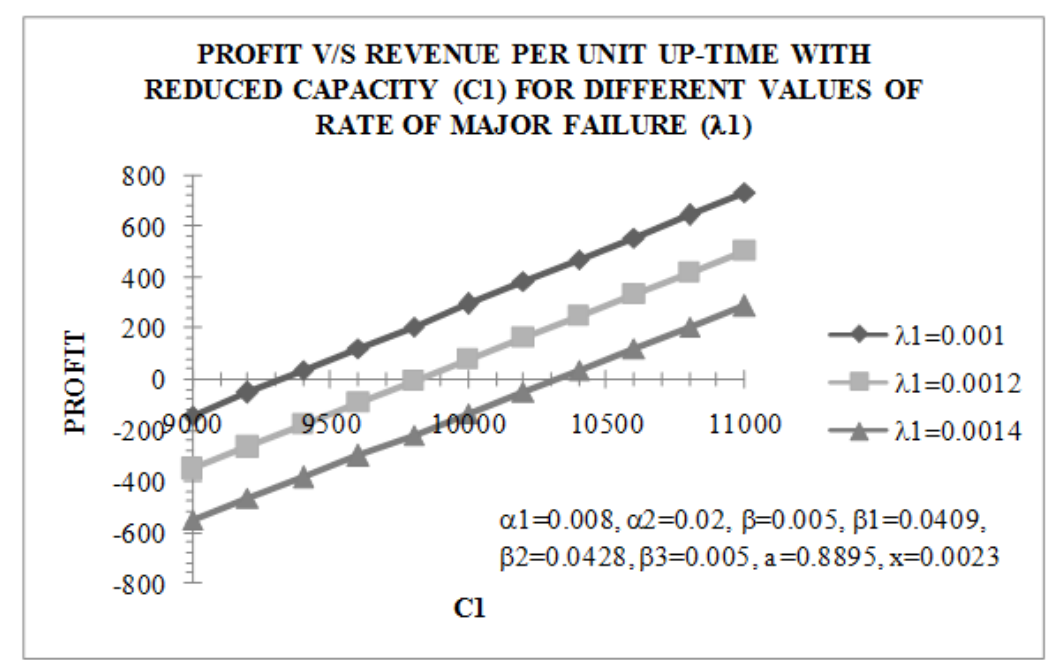

Fig. 7

Fig. 8 gives the graphs of profit of the system and revenue per unit up-time of the system with reduced capacity $\left(\mathrm{C}_{1}\right)$ for different values of repair rate $(\beta)$. The graph reveals that the profit of the system increases with increase in the values of revenue per unit up-time of the system with reduced capacity and repair rate. From the Fig.8 it may also be observed that for $\beta=0.018$, the profit is $<$ or $=$ or $>0$ according as $C_{1}$ is $<$ or $=$ or $>10301$. Hence the system is profitable to the plant whenever $C_{1}>$ Rs. 10301.00. Similarly, for $\beta=0.020$ and $\beta=0.022$ respectively the profit is $<$ or $=$ or $>0$ according as $C_{1}$ is $<$ or $=$ or $>9946.523$ and 9675.189 respectively. Thus, in these cases, the system is profitable to the plant whenever $C_{1}>$ Rs. 9946.523 and Rs. 9675.189 respectively.

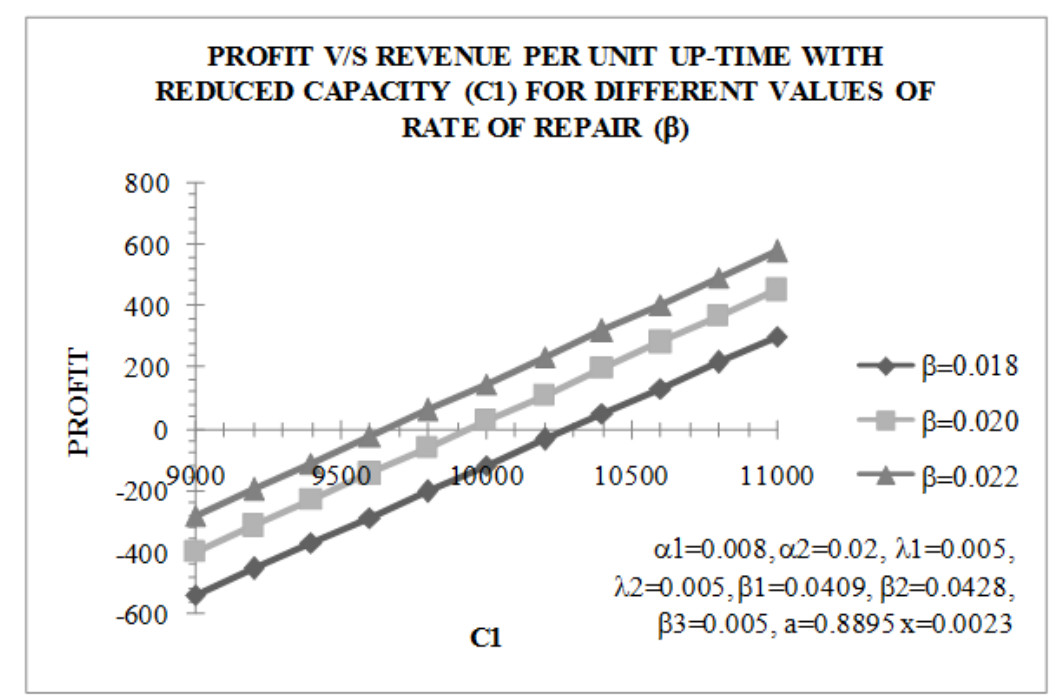

Fig. 8

\section{Conclusion}

From the graphical analysis it is concluded that the reliability and profit of the water process system decreases with the increase in the values of the rate of occurrence of the minor faults as well as major faults in the system. Also these decreases with increase in the values of the probability of a fault occurrence in a redundant subsystem of type-I. Also, the reliability and profit of the system increases with the increase in the values of the repair and inspection rates.

Various cut-off points for the profit of the system are obtained w.r.t. rates of occurrence of minor and major faults and revenue per unit up time of the system working with full capacity and reduced capacity. 


\section{References}

[1] Garg, R.C. and Kumar, A., “A complex system with two types of failure and repair”, IEEE Trans. Reliability, 26, 299-300 (1977).

[2] Goel, L.R., Sharma, G. and Gupta, R., "Reliability analysis of a system with prevention maintenance and two types of repairing", Microelectron Reliability, 26, 429-433 (1986).

[3] Gupta, M.L. and Kumar, A., "On profit consideration of a maintenance system with minor repair”, Micro-electron Reliability 23, 437-439 (1983).

[4] Kumar, R., Vashistha, U. and Tuteja, R.K., “A two-unit redundant system with degradation and replacement”, Pure and Applied Mathematika Science, LIV, No. 1-2, 27-38 (2001).

[5] Kumar, R., Sharma, M.K. and Mor, S.S., "Profit evaluation of a warranted sophisticated system with three operational stages", J. Indian Soc. Stat. Opers. Res., XXX, 53-61(2009).

[6] Kumar, R. and Bhatia, P., "Reliability and cost analysis of one unit centrifuge system with single repairman and inspection", Pure and Applied Mathematika Science, LXXIV, No. 1-2, 113-121(2011).

[7] Kumar, R. and Rani, S., "Reliability and availability analysis of a model on water process system having two types of redundant subsystems," Proceeding of National Seminar on Mathematical Modeling in Science \& Technology (NSMMST-2012), 20-23 (2012).

[8] Murari, K. and Goyal, V., "Reliability system with two types of repair facilities", Micro-electron Reliability, 23(6), 1015-1025 (1983). 